\title{
Precision of the paleomagnetic method: An example from the Quaternary Eifel volcanics (Germany)
}

\author{
Harald Böhnel ${ }^{1}$ and Elisabeth Schnepp ${ }^{2}$ \\ ${ }^{1}$ UNICIT-Instituto de Geofísica, Universidad Nacional Autónoma de México, Campus Juriquilla, Querétaro 76226, Mexico \\ ${ }^{2}$ NLfB-GGA, Arbeitsbereich Grubenhagen, OT Rotenkirchen, D-37574 Einbeck, Germany
}

(Received October 3, 1998; Revised June 7, 1999; Accepted June 14, 1999)

\begin{abstract}
The total within-site dispersion of paleomagnetic data results from natural misalignment processes and experimentally produced dispersion. Although some of the sources of dispersion may be determined by experiments, this is not possible for others. The total accuracy of the paleomagnetic method so far has been determined only on historic lava flows. Thirty-seven Quaternary basaltic lava flows from the Eifel, Germany, have been re-sampled using the same outcrops as before. The new site-mean directions do not differ significantly from those of the original study. The angular distance between pairs of site-mean directions may be approximated by a Fisher distribution. Assuming that both studies are affected by the same natural dispersion processes, we obtain as the best value for the experimental dispersion $s_{\exp }=4.33^{\circ}$. The total within-site dispersion shows a log-normal distribution with a mean of $s_{\text {tot }}=5.39^{\circ}$. From these values we calculate that the dispersion due to natural processes in the Eifel volcanic field is $s_{\text {nat }}=3.21^{\circ}$.
\end{abstract}

\section{Introduction}

The paleomagnetic method has made important contributions to many fields of the geosciences, including, for example, plate tectonics, studies of the Earth's magnetic field, and magnetostratigraphy. Application of the paleomagnetic method generally involves the determination of individual magnetic directions for multiple samples collected at one site, from which a site-mean direction is calculated. This method averages out a number of errors, which are thought to contribute randomly to the site-mean direction. Such errors are generated by natural variations of the magnetization directions at the scale of the site, and by experimental procedures during field and laboratory work. The total dispersion of the directions may be expressed by Fisher's (1953) precision parameter, $k$, and the angular standard deviation, $s$, which are interrelated by $s=81 / \sqrt{ } k$.

Under normal circumstances it is not possible to distinguish between the dispersion produced by natural directional variations of the magnetization and the dispersion due to experimental errors. For the case of historical lava flows, only a total accuracy of paleomagnetic data (rather than the paleomagnetic method) has been reported by Doell and Cox (1963) and by Holcomb et al. (1986). The knowledge of paleomagnetic data dispersion is important for applications like paleomagnetic dating, correlation, and paleosecular variation studies. In such applications observed site-mean directions are compared with reference data. For dating purposes for instance, the dispersion inherent in the site-mean directions imposes a lower limit on the resolution in time which may

Copy right $(\mathrm{C})$ The Society of Geomagnetism and Earth, Planetary and Space Sciences (SGEPSS); The Seismological Society of Japan; The Volcanological Society of Japan; The Geodetic Society of Japan; The Japanese Society for Planetary Sciences. be achieved by the paleomagnetic method.

In this paper we evaluate paleomagnetic data which were obtained from repeatedly studied rocks, with the aim of determining the contribution of experimental errors and thus to obtain a quantitative measure for the precision of the paleomagnetic method. At the same time, we can estimate the contribution of the natural directional variations of magnetization to the total dispersion of paleomagnetic data for the Eifel volcanic field, which should be characteristic of other volcanic fields in similar geological environments and with similar magnetic properties.

\section{Errors and Dispersion of Paleomagnetic Data}

The question of paleomagnetic data dispersion has recently been addressed by Hagstrum and Champion (1994), who studied 10 historic lava flows of Kilauea Volcano (Hawaii), each at 5 to 12 sites. Angular distances between site-mean directions varied from $0.2^{\circ}$ to $6.6^{\circ}$, with an average around $3^{\circ}$. In part, this was due to the detailed sampling with 12 cores, which reduced the $95 \%$ confidence circle and may have resulted in larger angular distances. Nevertheless, often this over sampling was not the true reason for that difference, as about $40 \%$ of the site-mean directions from the same lava flow were different at the $95 \%$ probability level (McFadden and Lowes, 1981). These differences were attributed to magnetic anomalies and flow deformation after remanence acquisition, resulting in a varying natural dispersion for different sites of the same flow. These data do not allow separation of the natural and experimental dispersion inherent in the site-mean directions, as both may have contributed by an unknown degree to the total dispersion. Of course, they present a very useful qualitative measure of the possible differences which may be found studying the same 
Table 1. Dispersion sources of paleomagnetic data, the circumstances where the dispersion has been observed, and the estimated or measured value for the dispersion, in terms of the angular standard deviation $s$.

\begin{tabular}{llcl}
\hline Error type & Observed in & Angular S.D. & Reference \\
\hline imperfect domain alignment & estimated only & $<4.5^{\circ}$ & Irving et al., 1961 \\
& estimated for Hawaii lavas & $<1.2^{\circ} \cdots 2.2^{\circ}$ & Doell and Cox, 1963 \\
fractures, cooling joints etc & estimated for Hawaii lavas & $<2.6^{\circ} \cdots 4.5^{\circ}$ & Doell and Cox, 1963 \\
& estimated for E-Eifel lavas & $<2.6^{\circ}$ & Kohnen and Westkämper, 1978 \\
paleo-field inhomogeneities & Hawaii lavas & $<2.4^{\circ}$ & Doell and Cox, 1963 \\
orientation errors & E-Eifel lavas & $<0.3^{\circ}$ & Kohnen and Westkämper, 1978 \\
actual magnetic anomalies & E-Eifel lavas & $<1.1^{\circ}$ & Kohnen and Westkämper, 1978 \\
orientation of samples & indist. from next error & & \\
remenance measurement & Digico magnetometer & $<0.3^{\circ}$ & Kohnen and Westkämper, 1978 \\
ARM, GRM, pTRM & Hawaii lavas & $<0.8^{\circ} \cdots 1.2^{\circ}$ & Doell and Cox, 1963 \\
& E-Eifel lavas & $<0.7^{\circ}$ & Kohnen and Westkämper, 1978 \\
determination of ChRM & anywhere & $?$ & \\
total dispersion & Hawaii lavas & $2.9^{\circ}$ & Holcomb et al., 1986 \\
\hline
\end{tabular}

lava flow in different outcrops.

Paleomagnetic data are dispersed because of natural processes producing directional variations of the remanence vector within the sampled rock unit (called natural dispersion), and because of experimental errors from the sampling and laboratory studies. Some of the contributing error sources have been studied for part of the data used here (Kohnen and Westkämper, 1978) or for other places (e.g., Doell and Cox, 1963) and are given in Table 1 in terms of angular standard deviations $s$. Other error sources so far have not been determined experimentally and only an estimated value is given.

Nature contributes to the dispersion of paleomagnetic data by imperfect alignment of magnetic domains $\left(<1.2^{\circ}\right.$ to $\left.4.5^{\circ}\right)$, local displacement of rock units along fractures, cooling joints or deformation after remanence acquisition $\left(<2.6^{\circ}\right.$ to $4.5^{\circ}$ ). Additionally, local anomalies present during the NRM-acquisition may deflect the remanence direction from the ambient field direction. Such anomalies depend on the magnetization of the underlying terrain and the topography of the sampled outcrop. For the East-Eifel volcanic field, Kohnen and Westkämper (1978) estimated that $s \leq 2.6^{\circ}$, although Baag et al. (1995) demonstrated that an error of as much as $20^{\circ}$ may be produced in extreme situations.

Many of the above contributions are expected to be random over a typical sampling site, and distributing the individual samples will reduce or eliminate them. Combining the above values results in a natural dispersion of $s<3.7^{\circ}$, if the lower values are used for each contribution (Table 1).

Experimental errors occur during field and laboratory work. The orientation of the drilled core is affected by reading errors $\left(s=0.3^{\circ}\right)$ and the transfer of the orientation mark on the core (no quantitative value available, but certainly much larger than $0.3^{\circ}$ ). The magnetic anomaly of the rock unit may deflect the magnetic compass used for orientation, contributing less than $1.1^{\circ}$ for the case of the East Eifel. The use of a sun compass eliminates this error but orientation is less precise that way. During the remanence measurement of samples, a positioning error occurs in the magnetometer which depends on the sensitivity and resolution of the instrument $\left(s<0.3^{\circ}\right.$ in a Digico magnetometer). During the demagnetization of rock samples, laboratory induced magnetizations may be produced, contributing $s<0.7^{\circ}$ to $1.2^{\circ}$. Other errors are introduced during the determination of the characteristic remanence direction (ChRM) from the demagnetization data, and for this again no quantitative data are available.

Non-random errors may also occur, for example by misorientation of samples during the field or laboratory work, or erroneous data analysis. Generally, such errors may be recognized as outliers using statistical methods and eliminated before the calculation of a site-mean direction. Otherwise they would produce a systematic error.

The combined contribution of the above experimental errors results in $s<0.8^{\circ}$, again using the lower value for each contribution in Table 1.

Holcomb et al. (1986) applied a similar analysis to paleomagnetic data from Hawaiian lava flows as did Doell and Cox (1963), to estimate the minimum resolution attainable for dating lava flows using paleomagnetic secular variation. Based on the study of 135 flows, and by combining estimates for the different contributing error sources, they estimated a total dispersion of $2.9^{\circ}$. As these data come from different lava flows, the total dispersion can not be split up into natural and experimental contributions. It should also be mentioned here that this value is already larger than the natural dispersion derived from Table 1, which could indicate that this method of determining a mean total dispersion underestimates the real value.

Alternatively, Hagstrum and Champion (1994) studied various Hawaii lava flows, each of them at several different 


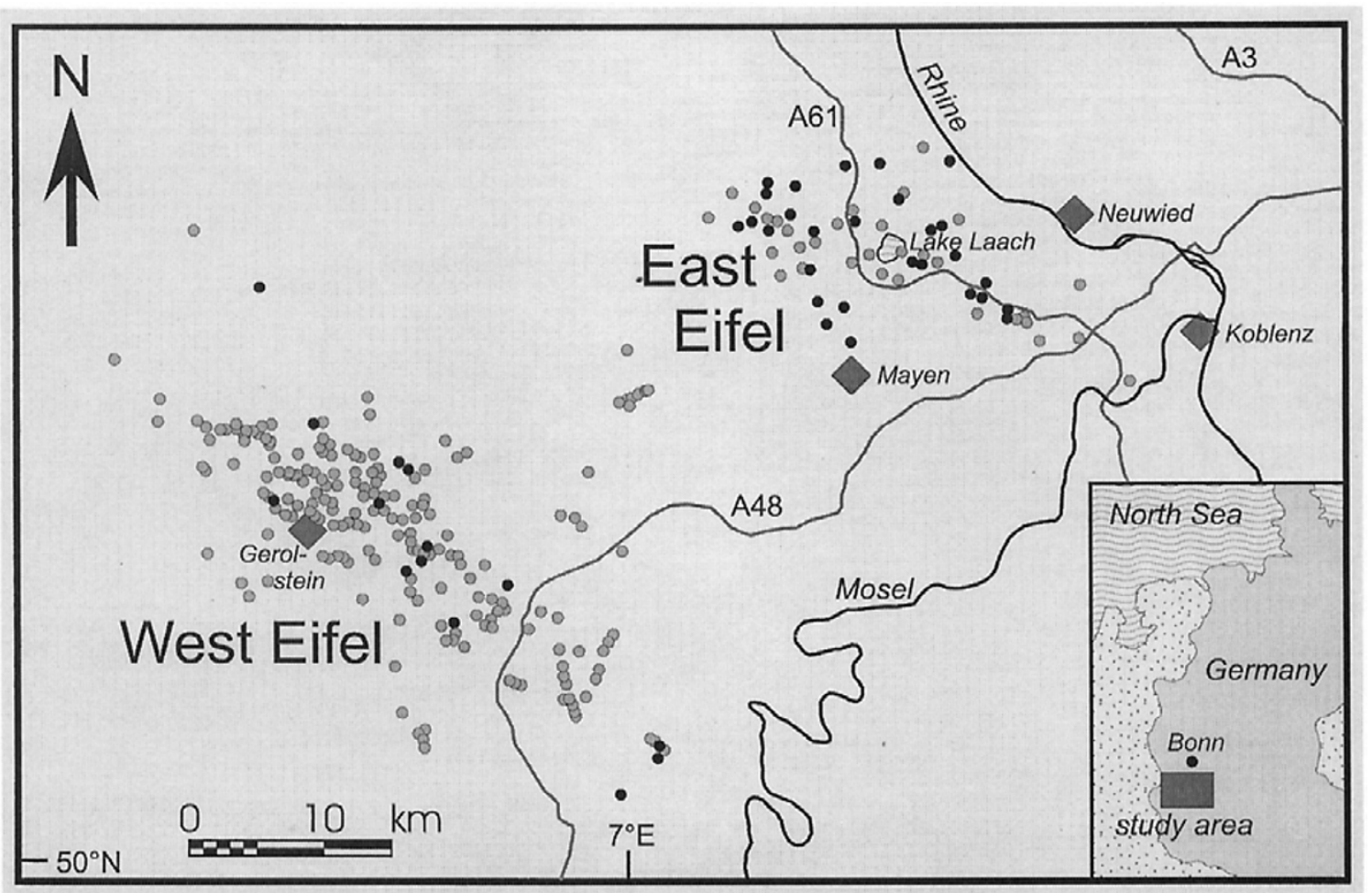

Fig. 1. Distribution of volcanic eruption centers in the Quaternary Eifel volcanic field, Germany (after Büchel and Mertes, 1982) shown as gray and black dots. Black dots indicate eruption centers used for the present study.

outcrops. They observed significantly differing site-mean directions for the same lava flow and attributed this to intraflow deformation and differing magnetic anomalies. Due to these varying conditions, the actual magnetic record may not be used to separate the total dispersion into its natural and experimental components.

The data present in this paper were obtained from exactly the same outcrops, so that the paleomagnetic record should be the same. This allows us to deduce the experimental and natural dispersion from the site-mean directions.

\section{The Data Sets}

The paleomagnetic data used for this study come from the Quaternary Eifel volcanic province in Germany (Fig. 1). More than 300 monogenetic volcanic centers of Quaternary age are known, distributed in the East- and West-Eifel fields with different eruption histories and paleomagnetic records (e.g. Böhnel et al., 1982, 1987; Fuhrmann and Lippolt, 1987; Bogaard and Schmincke, 1988; Schnepp and Hradetzky, 1994; Schnepp, 1996). The East-Eifel is characterized by basanitic, leucititic, nepelinitic, tephritic and phonolitic rocks spanning half of the Brunhes Chron. In the West-Eifel, rocks of leucitite and nephelinite composition dominate, followed by melilite-bearing foidites and other mafic rocks. The ages also cover a part of the Brunhes Chron, with a large percentage of volcanoes originating during a field-excursion about $510 \mathrm{ka}$ ago.

\subsection{Data from the first East-Eifel study}

The East-Eifel data define a paleopole close to the geographical north pole. The VGP-dispersion is consistent with commonly used models for the paleo secular variation of the earth's magnetic field (Kohnen and Westkämper, 1978). Samples were taken with a gasoline powered drill and oriented "in situ" with an inclinometer and a magnetic compass. The samples always were distributed all over the outcrop, to reduce as far as possible systematic errors as discussed above.

About $30 \%$ of all samples were demagnetized in detail with alternating fields (AF), and their characteristic remanent magnetization (ChRM) was determined using Zijderveld diagrams and stability indices. Based on the behavior of these pilot samples, the rest of the samples were then treated with one demagnetization step only, to obtain the corresponding site-mean direction. It should be mentioned here that only minor secondary remanence components were present in the samples, justifying such a procedure. Demagnetization curves always tended straight towards the origin of the Zijderveld diagrams. The high quality of the paleomagnetic data is clearly reflected by low within-site dispersion, high precision parameters $k$, and small confidence angles $\alpha_{95}$ (see Table 2). Field and laboratory work was done by Böhnel (1977) and by Westkämper (1977).

\subsection{Data from the first West-Eifel study}

Results from the West-Eifel are quite different, with a high percentage of low-latitude VGPs which are concentrated in a longitudinal sector. This observation was interpreted as the result of periodic eruption cycles, where a significant percentage of the lava flows were extruded during an excursion of the Earth's magnetic field (Böhnel et al., 1987; Schnepp, 1991). According to recent geochronological studies the excursion happened around $510 \mathrm{ka}$ ago (Schnepp and Hradetzky, 1994). Approximately one third of the samples in the West-Eifel were collected the same way 


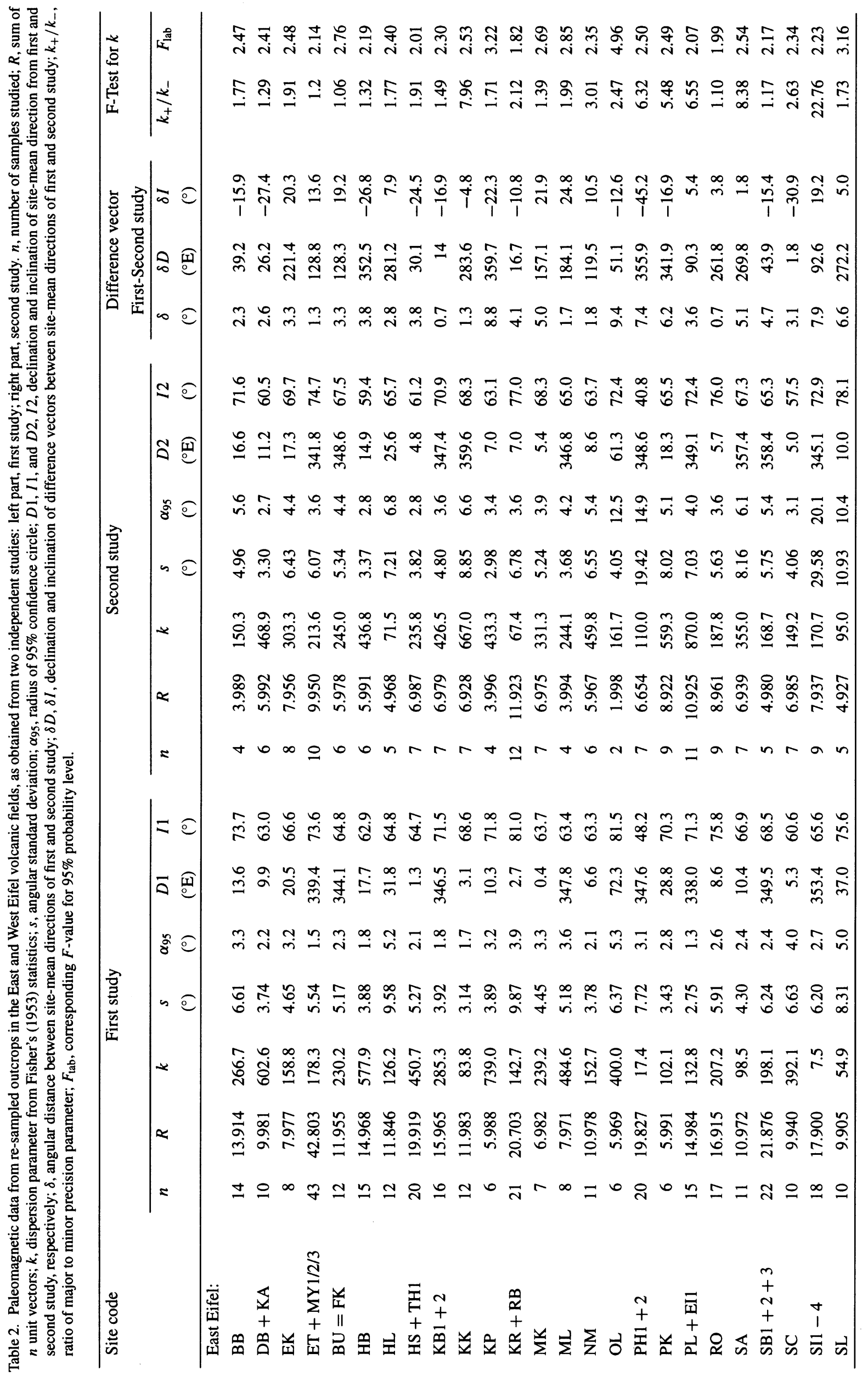




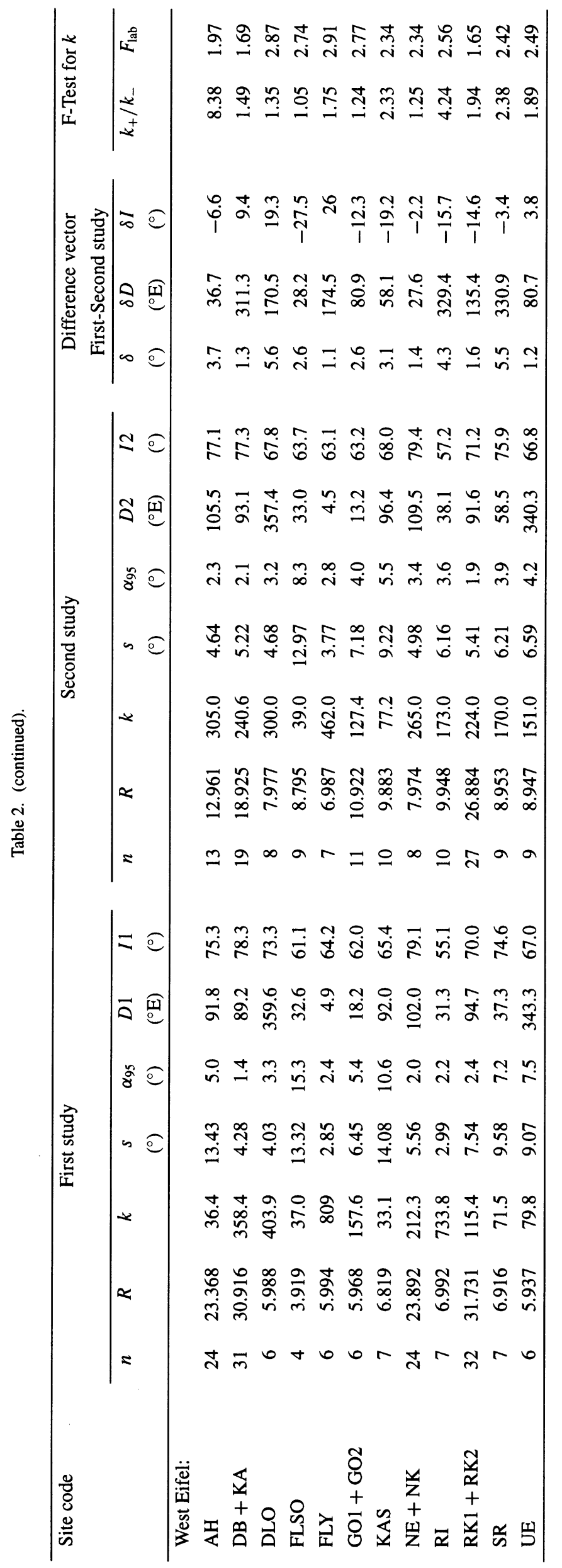


as described above, and the remaining two thirds with electrical drill equipment. Besides the magnetic compass, a sun compass was also used, although no systematic difference between the two orienting methods was found. The samples were mainly AF-demagnetized, but a small number were also subjected to thermal demagnetization. ChRM directions were obtained using Zijderveld diagrams, stability indices, difference-vector diagrams, and principal component analysis. Field and laboratory work were done by Haverkamp (1980), Jäger (1982), and Reismann (1985).

\subsection{Data from the second West-Eifel study}

Schnepp $(1991,1994)$ extended the work in the WestEifel to obtain paleointensities of the Earth's magnetic field. For the paleointensity experiments some untreated samples left by the previous workers could be used, but all sites had to be re-sampled at least partly. This was done in exactly the same outcrops as before, using the field notes of the previous workers. Several new sites have been studied as well, but these are excluded from the present study. Cores again were collected from different parts of the outcrop with an electrical drill, and magnetic and sun compasses were used for orientation. ChRM directions were obtained from thermal demagnetization experiments, which were carried out as part of the paleointensity determinations, using the double heating method of Coe (1967). ChRM directions are based mainly on Zijderveld- and difference-vector diagrams.

\subsection{Data from the second East-Eifel study}

Recently, the East-Eifel rocks have been re-studied to obtain paleointensities for comparison with the results from the western part (Schnepp, 1995, 1996). Only a few specimens were available from the former studies, so that all of the East-Eifel sites had to be re-sampled. Again, this was done in exactly the same outcrops sampled before. The same field

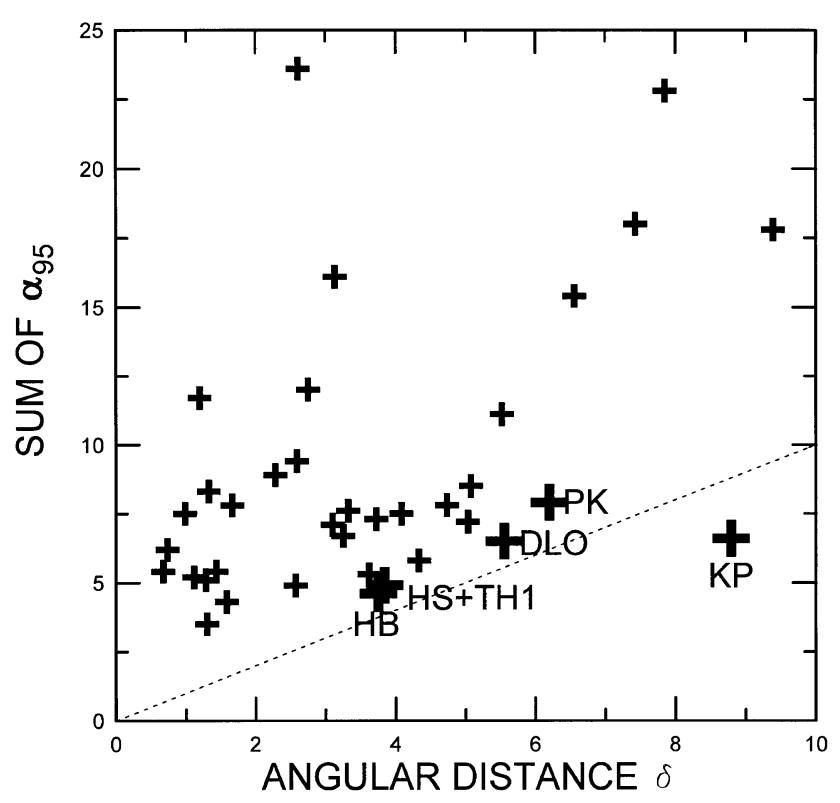

Fig. 2. Sum of confidence limits $\left(\alpha_{95}\right)$ of site-mean directions as obtained from repeated study of the same outcrop versus angular distance between the two observed site-mean directions. The dashed line indicates equality of both parameters. Larger symbols correspond to sites with significantly different mean directions and their labels correspond to Table 2. and laboratory procedures were applied as in the West-Eifel paleointensity study (see above).

Table 2 lists the two data sets, indicating the common statistical parameters for paleomagnetic results, and the difference vector and angular distance $(\delta)$ between the corresponding site-mean directions. The number of samples per site is larger for the new study in the case of the West Eifel, and smaller for the new study in the East Eifel, which is a consequence of the focus of the paleointensity work. Corresponding site-mean directions generally are in excellent agreement, with small, overlapping confidence circles, as demonstrated in Fig. 2. Here, the sum of the two error-circle radii $\left(\alpha_{95}\right)$ is plotted versus the angular distance between the two site-mean directions. Only one site from the East-Eifel has an angular distance slightly larger than the sum of errorradii. Application of the McFadden and Lowes (1981) test shows that the site-mean directions of entries KP, DLO, HB, $\mathrm{HS}+\mathrm{TH} 1$, and $\mathrm{PK}$ are different at the $95 \%$ probability level. The significance level for these sites varies between $99.9 \%$ and $97.3 \%$. This indicates that even when the same outcrop is resampled, the site-mean directions may differ significantly. Obviously this represents a problem for correlation or dating applications using paleomagnetism.

\section{Analysis of the Dispersion of Paleomagnetic Data}

The relation of the within-site dispersion and angular distance between corresponding site-mean directions with the rock magnetic parameters (NRM-intensity, median destructive field, Königsberger factor Q) was analyzed, and no significant differences were observed for the different studies. Apparently, these parameters have no influence on the dispersion of paleomagnetic data.

Every pair of site-mean directions in Table 2 corresponds to exactly the same outcrop and therefore the two precision parameters $(k)$ should not differ significantly, assuming that both data sets belong to the same population. In Fig. 3(a) the $k$ values are compared, and very large differences are observed which in part may be due to the varying number of samples. Applying the F-test (McFadden and Lowes, 1981, equation 24a) the significance of these differences is evaluated, and there is a considerable number of sites where the precision parameter $k$ differs at the $95 \%$ probability level (Fig. 3(b)). We conclude from this observation, that the statistical requirement of coinciding $k$ parameters for the same rock unit may be too strict in some real cases.

Now we evaluate if systematic differences exist between site-mean directions from the same site, which is done by looking at the corresponding unit-length difference vectors (Fig. 4). Most difference vectors have shallow inclinations and random declinations, as would be expected for site-mean directions which are almost parallel. The precision parameter of the resulting mean of difference vectors is $k<1$, indicating that there is no systematic difference between the directions of the two data sets.

The difference vectors are roughly distributed along a great circle oriented perpendicular to the overall mean direction of the study area, with a pole close to the overall mean direction (Fig. 4). This is due to the structure of the dipole field and the random difference in site-mean directions, resulting in neg- 


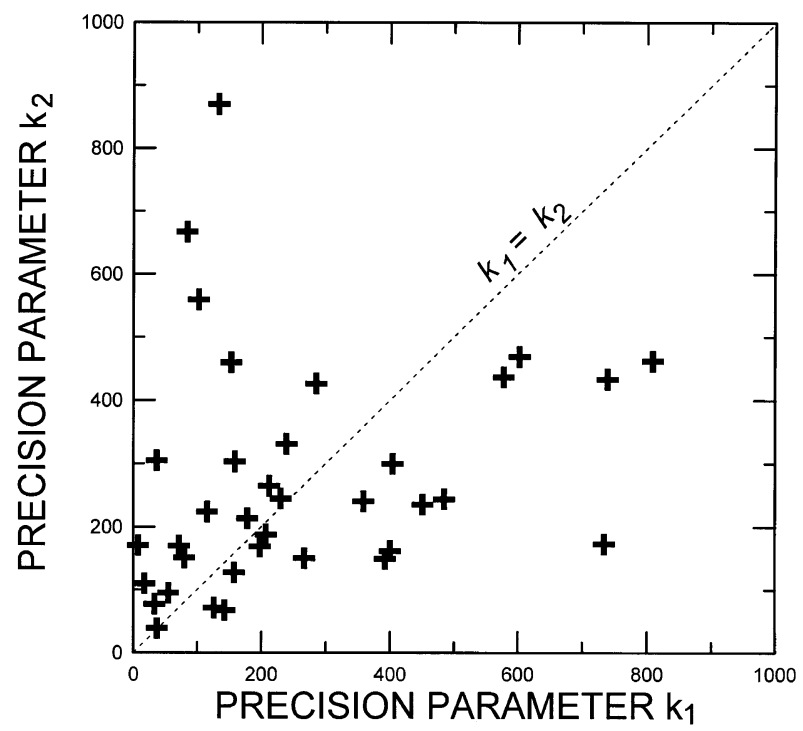

a)

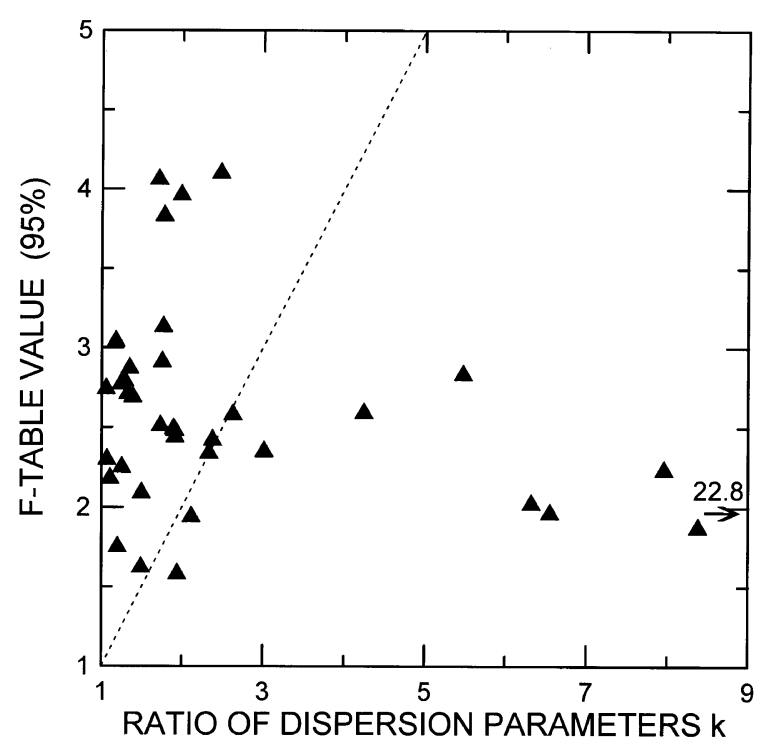

b)

Fig. 3. (a) Comparison of dispersion parameters $k_{1}$ and $k_{2}$ from first and second study, respectively. (b) Significance test (McFadden and Lowes, 1981) for dispersion parameters $k$ : If data lie below the dashed line, the corresponding $k$ parameters are different at the $95 \%$ probability level.

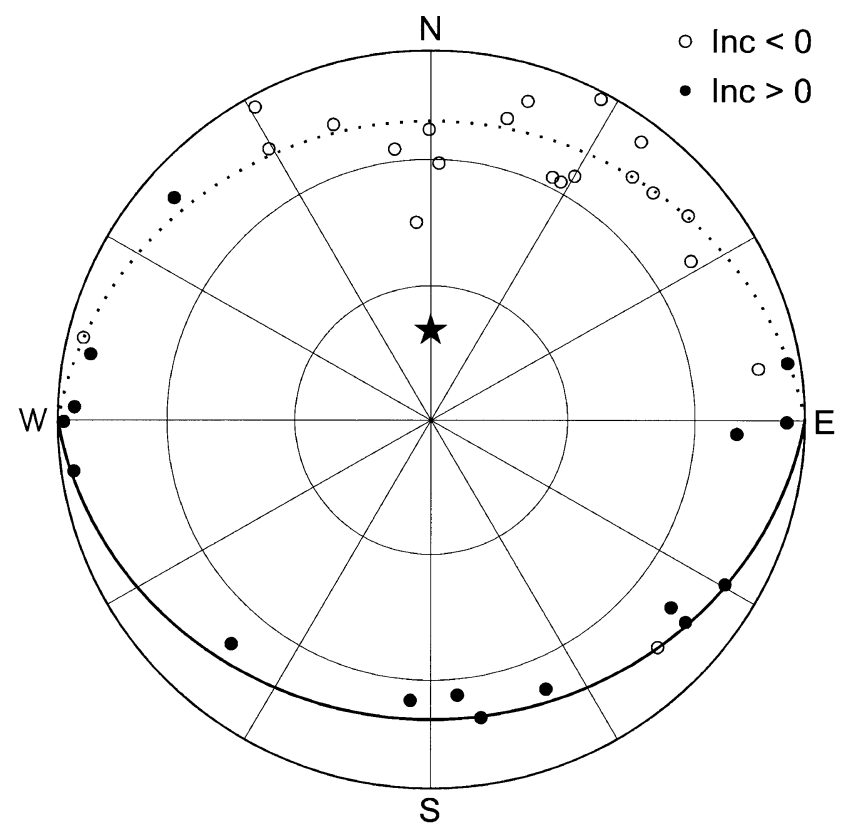

Fig. 4. Unit-length difference vectors between corresponding site-mean directions in equal area projection. The approximate overall mean direction of the Eifel paleomagnetic data is shown by a star and the great circle around that direction by a thick line (dotted where inclination is negative).

ative (positive) and increasingly steeper difference vectors in north (south) direction, if compared with the shallower difference vectors in east and west directions. Inverting the site-mean directions used for the difference vector calculation, the observed great circle would change its inclination from south to north.

Based on the combined evidence of above observations, we conclude that the directional differences between each pairs of site mean directions are random with no significant bias due to experimental procedures.

As corresponding site-mean directions differ randomly, the dispersion of the difference vectors may be described by directional statistics. The angular distances $\delta$ which describe the radial component of the difference vectors should follow a Fisher (1953) distribution, which is a spherical analogue to the Gauß distribution of random one-dimensional variables. This angular distance is assumed to represent the contribution of the experimental errors, as each site mean direction on its own represents a sample of a data population which is disturbed by the same natural dispersion, but by differing experimental dispersions (different conditions during field and laboratory work, different operators, etc).

Figure 5 shows histograms of observed angular distances, using $1^{\circ}$ and $2^{\circ}$ class widths, respectively. A Fisher distribution was adjusted to the data, and by means of the $\mathrm{Chi}^{2}$-test the statistical significance of this approximation was tested. The continuous lines in Fig. 5 represent the best-fit Fisher distribution to the data which was determined by variation of the precision parameter $k$, taking the $k$-value where $\mathrm{Chi}^{2}$ achieved a minimum as shown in the curves of Fig. 6. The minima are well defined and significant at the $95 \%$ confidence level, and the observed distribution therefore is indistinguishable from a Fisher distribution with precision parameters $k=350$ and $k=368$, for the chosen class-widths (Fig. 5). For a $1.4^{\circ}$ class width (not shown) the best-fit is defined by $k=347$. The difference between these approximations is small, demonstrating that the obtained value for $k$ is stable and rather independent of the chosen class width of $\delta$. The standard angular deviation may be estimated according to $s=81 / \sqrt{ } k$ (Fisher, 1953), giving a value for $s$ of $4.33^{\circ}$ from $k=350$. This standard angular deviation is characteristic for the experimental dispersion of a site-mean 


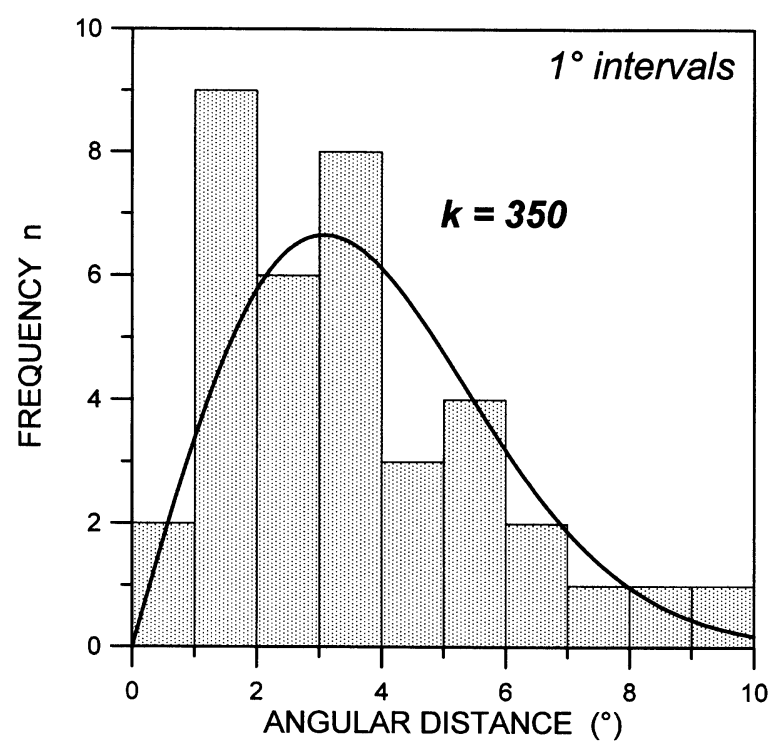

(a)

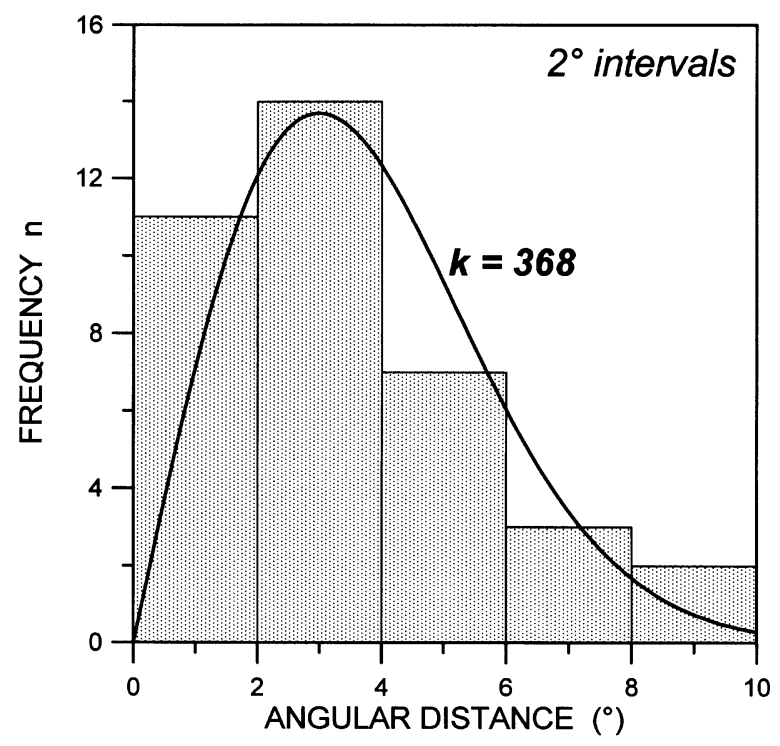

(b)

Fig. 5. Histogram of observed angular distances $\delta$ between corresponding site-mean directions for of (a) $1^{\circ}$, and (b) $2^{\circ}$ class-widths of $\delta$. The curves in both histograms indicate the best-fit Fisher distribution to the histograms, with the corresponding value of dispersion parameter $k$ indicated along the curve.

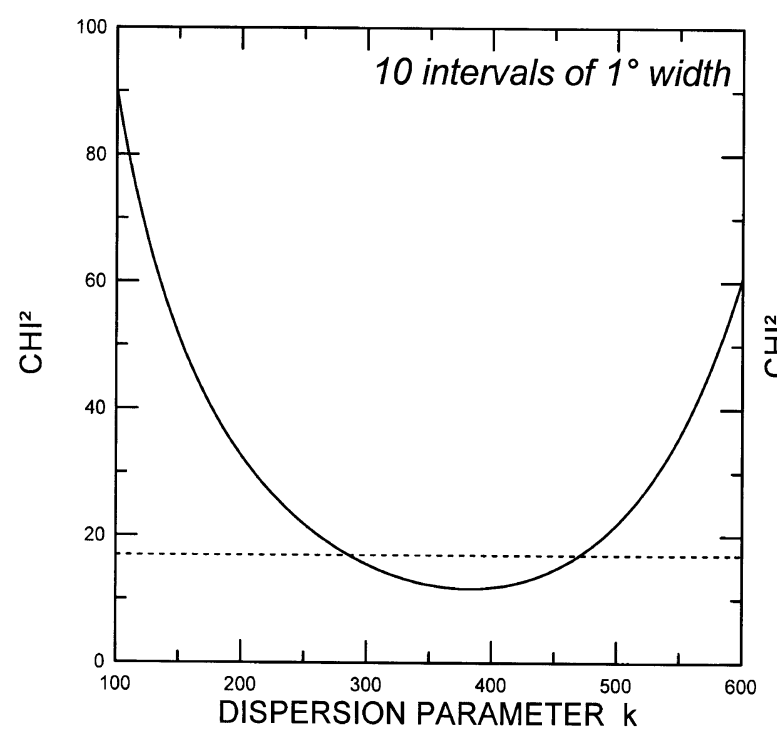

(a)

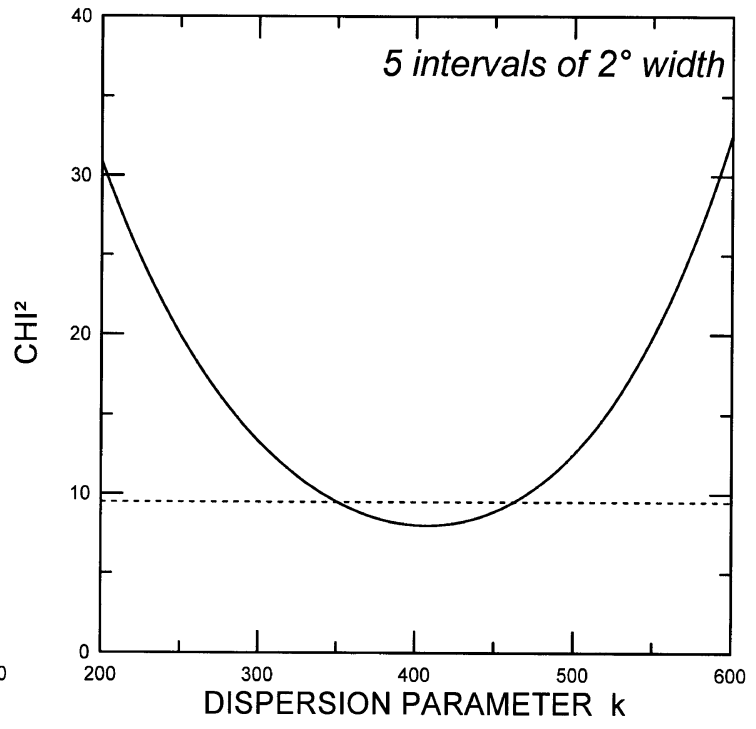

(b)

Fig. 6. Variation of dispersion parameter $k$ as a function of the value of $\mathrm{Chi}^{2}$-test, for (a) $1^{\circ}$, and (b) $2^{\circ}$ class widths of angular distances $\delta$. Horizontal dashed lines indicate the $95 \%$ significance level.

direction in the Quaternary Eifel volcanic field, assuming that the natural dispersion is the same for the two studies because exactly the same outcrops were re-sampled.

\section{Discussion}

By analyzing the within-site dispersion $(s=81 / \sqrt{ } k$ ) of all site-mean directions (first and second studies), we observe a log-normal distribution of $s$ (Fig. 7) which is expected because there are no negative or very small values of $s$. Al- though we would like to mention that no theoretical argument is available to prove such a distribution for a data set like ours. The distribution is centered at $\log (s)=0.731$, or $s=5.39^{\circ}$. As the total within-site dispersion $\left(s_{\mathrm{tot}}\right)$ is the sum of contributions from natural processes and experimental factors, we can separate them according to:

$$
s_{\text {nat }}^{2}=s_{\text {tot }}^{2}-s_{\text {exp }}^{2} \text {, }
$$




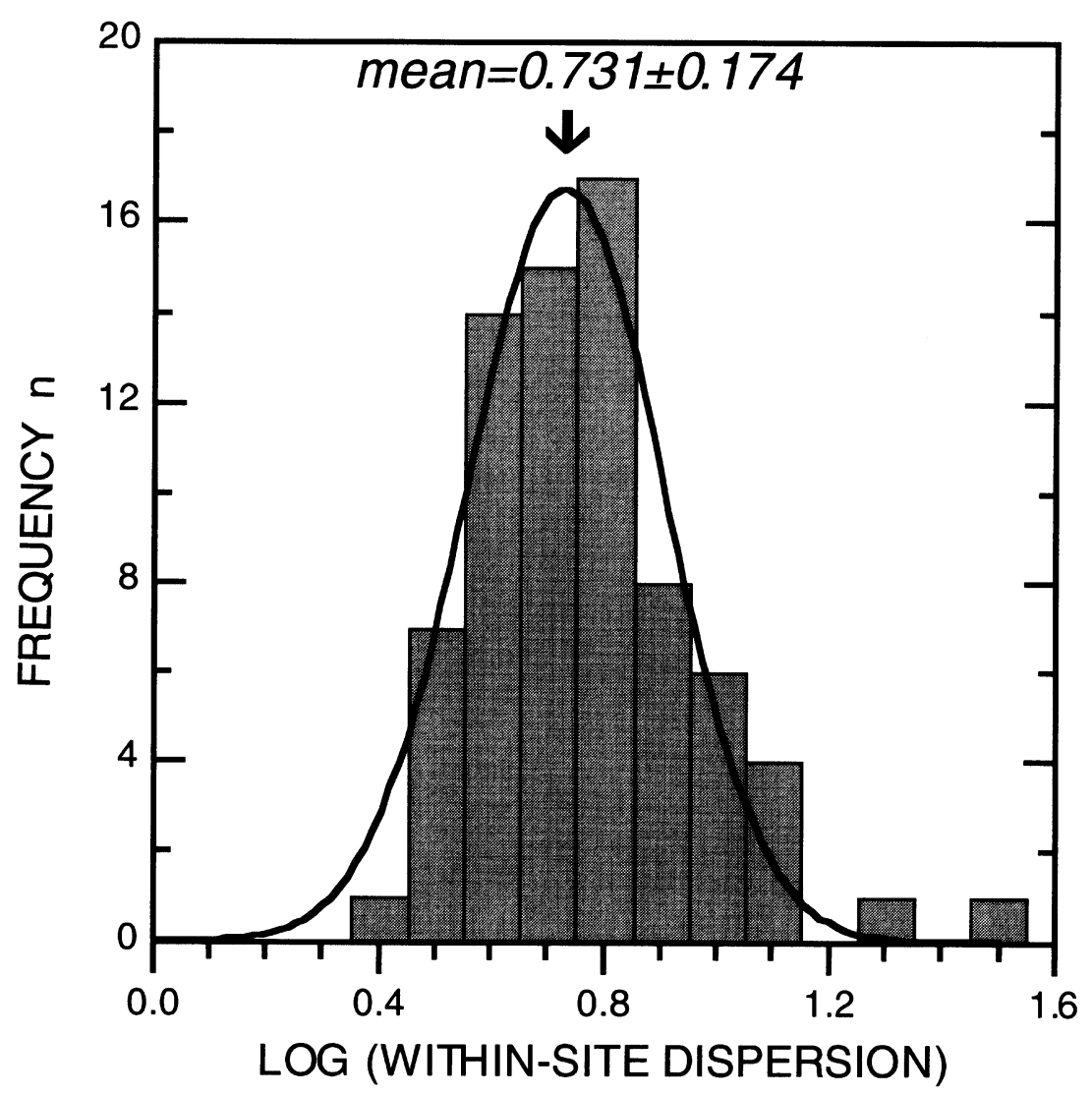

Fig. 7. Histogram of within-site angular standard deviation $s$, using logarithmic class-width subdivision of $s$.

where $s_{\text {nat }}$ and $s_{\text {exp }}$ denote the dispersions due to natural processes and experimental procedures, respectively. Using the above values, we then obtain $s_{\text {nat }}=3.25^{\circ}$. This is the dispersion present in the Eifel volcanic rocks as a consequence of natural processes, which were mentioned above: imperfect alignment of magnetic domains, minor movement of the rocks after TRM acquisition, and deflection of the TRM because of the presence of local anomalies of the ambient field. As this kind of contribution to the total within-site dispersion may not be reduced experimentally, it presents the "back-ground noise" inherent to a paleomagnetic study in similar geological environments as the Eifel. Even with sophisticated field and laboratory equipment, the experimental methods only will add to that dispersion. Comparing the natural and experimental contributions to the dispersion, large efforts to improve paleomagnetic instruments and methods will not have much effect, at least for the study of volcanic rocks: reducing the experimental dispersion to $2^{\circ}$ would still give a total dispersion of $s=3.8^{\circ}$. The situation of course may change for rocks of low remanence intensity, where measurement errors and natural processes disturbing the alignment of remanence within the rock increase considerably, and it would be very interesting to perform a similar comparative study on such rocks. In most sedimentary rocks the secular variation of the earth's magnetic field will also contribute to the natural dispersion.

The obtained value of $3.21^{\circ}$ for the natural dispersion compares well with data listed in Table 1, which give a combined value of $s<3.7^{\circ}$ (see above), indicating that the estimated error values are indeed reasonable. On the other hand, this value is already larger than the total dispersion of $2.9^{\circ}$ estimated by Holcomb et al. (1986) for Hawaiian lava flows. This difference could be due to varying geological conditions, but we believe that it is due to the different methods used to determine the dispersion of the paleomagnetic data.

The value of $4.33^{\circ}$ derived for experimental errors is much larger than the combined value of $s<1.6^{\circ}$ from Table 1 . We believe that this is mainly due to the unknown contribution of errors in marking and orienting the samples. It is easy to imagine that the mark scribed on the sample during the orientation in the field and later transferred to the whole cylinder may have errors of several degrees, in terms of an azimuthal angle with respect to the cylinder axis. A similar error occurs while registering this mark in the magnetometer during the remanence measurements. The determination of the ChRM direction from the demagnetization data by any method may increase the dispersion additionally. Using the minimum values from Table 1 and the experimental dispersion calculated in the present paper, these errors together contribute $\sim 4^{\circ}$ to the total dispersion.

\section{Conclusions}

We have discussed the possible contributions to the withinsite dispersion of paleomagnetic directions, which may be grouped into naturally and experimentally produced dispersions. For the individual processes involved, measured or 
only estimated numerical values are available. Based on the repetition of paleomagnetic studies of 37 Quaternary lava flows in the Eifel volcanic field (Germany) we analyzed the differences of the site-mean directions obtained. These sitemean directions differ randomly and in most cases insignificantly, and the angular distances between corresponding direction-pairs may be described by Fisher statistics. As the natural dispersion is assumed to be the same for both studies, the differences must be due to the experimental procedures. The Fisher statistics give a best value for the angular standard deviation of $s_{\exp }=4.33^{\circ}$, which we interpret to represent the mean experimental dispersion of the paleomagnetic studies in the Eifel. Most of this dispersion is likely (or most likely) due to errors during the orientation of the samples in the field and during the measurements.

By analyzing the total within-site dispersion, we obtain a mean value of $s_{\text {tot }}=5.39^{\circ}$, assuming that it is log-normal distributed. Using these data we find a value of $s_{\text {nat }}=3.25^{\circ}$ for the natural dispersion. The natural dispersion represents an important contribution to the total within-site dispersion, and it is impossible to improve the experimental methods such that the total dispersion will be reduced significantly.

This should be different for paleomagnetic studies of lowremanence rocks like limestone, where, apart of the differences in remanence acquisition, the experimental errors are much higher than in volcanic rocks.

Acknowledgments. The continuous support of the Eifel studies by Jürgen Untietd is acknowledged. These studies were supported by funds of the Deutsche Forschungs Gesellschaft. Reviews of Laurie Brown (previous version) and the journal referees (Jonathan Hagstrum and one anonymous reviewer) enhanced the manuscript and are appreciated.

\section{References}

Baag, C., C. E. Helsely, S. Z. Xu, and B. R. Lienert, Deflection of paleomagnetic directions due to magnetization of underlying terrain, J. Geophys. Res., 100, 10013-10027, 1995.

Bogaard, P. van den and H.-U. Schmincke, Aschenlagen als quartäre Zeitmarken in Mitteleuropa, Die Geowissenschaften, 30, 75-84, 1988.

Böhnel, H., Paläomagnetische Untersuchungen an quartären Vulkaniten der Osteifel, Diplom. thesis, Inst. Geophys. Münster, 1977.

Böhnel, H., H. Kohnen, J. Negendank, and H.-U. Schmincke, Paleomagnetism of Quaternary volcanics of the East-Eifel, Germany, J. Geophys., 51, 29-37, 1982.

Böhnel, H., N. Reismann, G. Jäger, U. Haverkamp, J. F. W. Negendank, and H.-U. Schmincke, Paleomagnetic investigation of Quaternary West Eifel volcanics (Germany): indication for increased volcanic activity during geomagnetic excursion/event?, J. Geophys., 62, 50-61, 1987.
Büchel, G. and H. Mertes, Die Eruptionszentren des Westeifeler Vulkanfeldes, Z. dt. geol. Ges., 133, 409-429, 1982.

Coe, R. S., The determination of paleointensities of the earth's magnetic field with emphasis on mechanisms which could cause non-ideal behaviour in Thellier's method, J. Geomag. Geoelectr., 19, 157-179, 1967.

Doell, R. R. and A. Cox, The accuracy of the paleomagnetic method as evaluated from historic Hawaiian lava flows, J. Geophys. Res., 68, $1997-$ 2009, 1963.

Fisher, R. A., Dispersion on a sphere, Proc. R. Soc. London, A127, 295-305, 1953.

Fuhrmann, U. and H. J. Lippolt, Excess argon and dating of Quaternary Eifel volcanism: III. Alkali basaltic rocks of the Central West Eifel/FR Germany, Neues Jg. Geol. Paläont. Mh., H4, 213-216, 1987.

Hagstrum, J. T. and D. E. Champion, Paleomagnetic correlation of late Quaternary lava flows in the lower east rift of Kilauea volcano, Hawaii, J. Geophys. Res., 99, 21679-21690, 1994.

Haverkamp, U., Paläomagnetische Untersuchungen an quartären Vulkaniten der Westeifel, Diplom. thesis, Inst. Geophys. Münster, 1980.

Holcomb, R., D. Champion, and M. McWilliams, Dating recent Hawaiian lava flows using paleomagnetic secular variation, Geol. Soc. Am. Bull., 97, 829-839, 1986.

Irving, E., P. M. Stott, and M. A. Ward, Demagnetization of igneous rocks by alternating magnetic fields, Phil. Mag., 6, 225-241, 1961.

Jäger, G., Paläomagnetische Untersuchungen im quartären Vulkanfeld der Westeifel, Diplom. thesis, Inst. Geophys. Münster, 1982.

Kohnen, H. and H. Westkämper, Paleosecular variation studies of the Brunhes epoch in the volcanic province of the East-Eifel, Germany, J. Geophys., 44, 545-555, 1978.

McFadden, P. L. and F. J. Lowes, The discrimination of mean directions drawn from Fisher distributions, Geophys. J. R. astr. Soc., 67, 19-33, 1981

Reismann, N., Abschließende paläomagnetische Untersuchungen zur Verteilung der virtuellen geomagnetischen Pole für das quartäre Vulkanfeld der Westeifel, Diplom. thesis, Inst. Geophys. Münster, 1985.

Schnepp, E., Die erdmagnetische Paläointensität im quartären Vulkanfeld der Westeifel, Ph.D. thesis, Inst. Geophys. Münster, 1991.

Schnepp, E., Determination of geomagnetic palaeointensities from the Quaternary West Eifel volcanic field, Geophys. J. Int., 116, 688-714, 1994

Schnepp, E., Paleointensity study of Quaternary East Eifel phonolithic rocks (Germany), Geophys. J. Int., 121, 627-633, 1995

Schnepp, E., Geomagnetic paleointensities derived from volcanic rocks of the Quaternary East Eifel field, Germany, Phys. Earth Planet. Int., 94, 23-41, 1996.

Schnepp, E. and H. Hradetzky, Combined paleointensity and ${ }^{40} \mathrm{Ar} /{ }^{39} \mathrm{Ar}$ age spectrum data from volcanic rocks of the West Eifel field (Germany): Evidence for an early Brunhes geomagnetic excursion, J. Geophys. Res., 99, 9061-9076, 1994.

Watson, G. S., Analysis of dispersion on a sphere, Mon. Not. R. astr. Soc., Geophys. Suppl., 7, 153-159, 1956.

Westkämper, H., Untersuchungen zur Paläosäkularvariation des Pleistozäns in der quartären Vulkanregion der Osteifel, Diplom. thesis, Inst. Geophys. Münster, 1977.

H. Böhnel (e-mail: harald@tonatiuh.igeofcu.unam.mx) and E. Schnepp (e-mail: grubenhagen@t-online.de) 